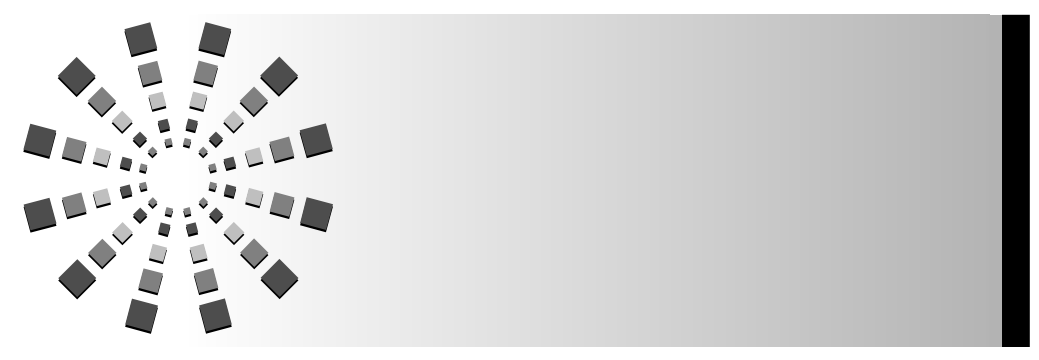

Diane Von Ah, PhD, RN

Mary Spath, PhD, RN

Adele Nielsen, BSN, RN

Betsy Fife, PhD, RN

\title{
The Caregiver's Role Across the Bone Marrow Transplantation Trajectory
}

\section{$\begin{array}{llllllll}\text { K } & E & Y & \text { W } & \text { O } & R & \text { D } & S\end{array}$}

Adaptation

Bone marrow transplant

Caregivers

Coping

Life satisfaction

Stress

This is the author's manuscript of the article published in final edited form as:

Von Ah, D., Spath, M., Nielsen, A., \& Fife, B. (2015). The Caregiver's

Role Across the Bone Marrow Transplantation Trajectory. Cancer nursing.

http://dx.doi.org/10.1097/

NCC.0000000000000242
Background: Approximately 50000 people undergo bone marrow transplants (BMTs) each year worldwide. With the move to more outpatient and home care, family caregivers are playing an ever-increasing role. However, there is little information regarding the needs and well-being of caregivers of individuals undergoing BMT. Objective: The study purpose was to gain a better understanding of the BMT experience across the trajectory from the perspective of the family caregiver. Methods: Qualitative interviews were conducted with 15 family caregivers during and 4 months after BMT. Interviews were recorded, transcribed verbatim, and analyzed using a content analysis approach. Results: Uncertainty and need for more information were 2 major underlying themes noted across the early BMT trajectory. Caregivers reported feeling overwhelmed and juggling multiple roles, including (a) "interpreter," which included obtaining and translating medical information to their partner, family, and social network; (b) "organizer," which included arranging and coordinating medical appointments (pre- and post-BMT) for the patient, but also juggling the needs of immediate and extended family members; and (c) "clinician," which included assessing and identifying changes in their significant other, with many reporting that they had to be "vigilant" about or "on top of" any changes. Caregivers also reported the most challenging aspects of their role were to "be strong for everyone" and "finding balance." Conclusions: Our results underscore the unique needs of family caregivers as a consequence of BMT. Implications for Practice: A greater understanding of the adaptation of caregivers will lead to the development of effective interventions for families going through BMT.
Author Affiliations: Department of Community and Health Systems, Indiana University School of Nursing, Indianapolis.

Funding for this study was provided by the American Cancer Society (RSGPB05-012-01-CPPB, principal investigator: Dr Fife).

The authors have no conflicts of interest to disclose.
Correspondence: Diane Von Ah, PhD, RN, Department of Community and Health Systems, Indiana University School of Nursing, 1111 Middle Dr, Indianapolis, IN 46202 (dvonah@iu.edu).

Accepted for publication December 18, 2014.

DOI: $10.1097 /$ NCC. 0000000000000242 
B one marrow transplant (BMT) is an aggressive medical procedure that has been increasingly used to address lifethreatening illnesses. In fact, more than 50000 BMTs are conducted annually worldwide, with approximately 18000 taking place in the United States alone. ${ }^{1}$ Bone marrow transplants are characterized by prolonged hospitalizations, intensive immunosuppressive therapies, and potentially life-threatening complications. Bone marrow transplant is a physically and psychologically demanding treatment, but it offers recipients hope and a final attempt at a cure.

The demands of the BMT can be a significant source of stress not only for the recipient, but also for the committed partner or spouse caregiver. ${ }^{2}$ Advances in treatment and cost-containment measures have resulted in more care being moved from the inpatient hospital unit to the outpatient setting and home care. Caregivers, therefore, are playing an ever-increasing role in the care of their partner across the BMT trajectory. ${ }^{3}$ Although researchers have demonstrated that committed partner/spouse caregivers are "willing to do whatever it takes" to care for their loved ones, ${ }^{4}$ little is known regarding the specific problems caregivers face across the BMT trajectory.

The purpose of this article is to present interview data that will lead to a better understanding of the BMT experience from the perspective of the committed partner/spouse caregiver during the early BMT trajectory. Findings from this work will be used to gain greater insight and understanding concerning the complexity and specific challenges of the caregiver role. In addition, based on the data, we conclude with recommendations for interventions aimed to promote positive adaptation for these families.

\section{- Background}

Caregivers play an integral role in the recipient's recovery and adaptation after BMT. Researchers have found that the lack of committed partner/spouse caregivers can both limit the use of outpatient stem cell transplant services ${ }^{5}$ and impact survival outcomes for the BMT recipient. ${ }^{6,7}$ In a retrospective study, Foster and colleagues $^{7}$ found that patients with a partner who stayed with them during their allogeneic transplant were 3 times more likely to be living 1 year after transplant. In a follow-up prospective study, these researchers validated the positive impact of the family caregiver during hospitalization, noting an increase in overall survival and relapse-free survival for BMT recipients who had the support of an in-hospital family caregiver compared with those who did not have this support. ${ }^{6}$ Taken together, these findings reaffirm the important role the caregiver has on outcomes across the BMT trajectory.

Caregivers, however, may experience significant distress. ${ }^{2,8-11}$ In fact, multiple studies have identified that committed partner/ spouse caregivers often have higher levels of distress than do their recipient partners. ${ }^{12,13}$ Researchers have also noted that committed partner/spouse caregivers often experience increased levels of depression and anxiety 9,11 and less dyadic satisfaction ${ }^{9,12}$ and that caregiving may impact their ability to work, resulting in financial concerns. ${ }^{14}$ However, few studies have qualitatively explored the specific challenges of the transplant experience from the perspective of the caregiver, ${ }^{3,15}$ and researchers have identified the need for more research to understand the quality of life of caregivers of cancer patients. ${ }^{16}$

Stetz and colleagues ${ }^{15}$ were among the first researchers to qualitatively explore the needs of caregivers of BMT recipients during treatment. These authors identified the need for nurses to provide informational support and promote self-care among committed partner/spouse caregivers during BMT. Wilson and colleagues ${ }^{3}$ also focused on understanding the experience of the caregiver during inpatient hospitalization for BMT. These researchers found that caregivers experienced a great deal of uncertainty during hospitalization, describing the experience as "riding on a rollercoaster in the dark." Although informative, these studies failed to address the entire BMT trajectory, specifically, the actual needs of the caregiver upon returning home. This is important because the BMT process often results in many long-term adverse effects such as graft-versus-host disease, which can compromise quality of life and result in the need for ongoing, long-term caregiving. In addition, an understanding of the experiences of the caregiver role across the entire BMT trajectory is needed to identify appropriate interventions to assist caregivers in their role. ${ }^{11}$ The main objective of this article is to report data from the perspective of the committed partner/spouse caregiver that will lead to a better understanding of the BMT experience across the early trajectory.

\section{- Methods}

\section{DESIGN}

A qualitative descriptive design was utilized to explore the phenomenon. ${ }^{17}$ Participants in this study were part of a larger descriptive study to examine adaptation of patients and their families prior to and up to 12 months after hospitalization for BMT. ${ }^{2}$ The study was approved by the cancer center review committee and the university institutional review board.

\section{PROCEDURE}

A convenience sample of committed partner/spouse caregivers of BMT patients from the larger study was recruited. Eligible participants included spouses and/or partners (significant others) who were living with the BMT recipient prior to transplant and who would assume the primary caregiver role during the transplant trajectory. Interviews were conducted at 2 time points: during hospitalization (T1) and 1 to 4 months after hospitalization (T2). Interviews were guided by a semistructured questionnaire, conducted over the phone, and tape recorded. Data were transcribed verbatim, and the accuracy of the transcripts was verified by the research staff.

During hospitalization (T1), the focus of the interview was to understand the experience of the pre-BMT and acute care hospitalization stay from the perspective of the caregiver. The initial interview began with the interviewer asking the caregiver to relay "their story" prior to and during the acute care phase of the BMT. Three open-ended, probing questions were also used to guide this 
interview: (1) How did you and your partner decide on having a BMT? (2) What has been the most challenging and difficult part of the waiting and preparation time? (3) What has been the most difficult part of the hospitalization period on you and your family?

The second interview occurred 1 to 4 months after hospitalization (T2), once the BMT recipient had successfully returned to the home setting. The goal of this interview was again to allow the caregiver the opportunity to describe "their story," including identifying the patient's needs and recovery and their experience as a caregiver to a spouse/significant other who had undergone a BMT. Probing questions included the following: (1) What has been the most challenging and difficult part of the posttransplant period? (2) What, if any, positive experience or changes have occurred since becoming a caregiver? and (3) What, if any, specific things could the transplant team do to make this time less distressing for families?

At both time points, we allowed the participants time to reflect on their experiences and had them provide examples whenever possible. Additional probing questions were used as needed to clarify responses. The interviews with caregivers lasted an average of 45 minutes.

\section{Data Analysis}

Data were analyzed to get a sense of the experiences of BMT families from the perspective of the committed partner/spouse caregiver. A conventional content analysis approach was used. ${ }^{17,18}$ In this type of analysis, research questions rather than a theoretical framework drive the analysis. ${ }^{18}$ The advantage of this approach is that the knowledge generated from it "is based on participants' unique perspectives and grounded in the actual data."18(p1279) Common themes across all the participants' data were identified and organized into clusters and categories. Full descriptions of the common themes of the experience were developed. All data were analyzed independently by 2 team members and compared, and interpretations were agreed upon. The raw data and subsequent themes were presented to a third team member for consensus. This article describes our predominant findings.

\section{Results}

\section{Sample Description}

A total of 15 committed partner/spouse caregivers completed the first interview during hospitalization (T1) and 9 caregivers who were 1 to 4 months after discharge completed a second follow-up interview (T2). We were unable to follow up with 6 of the original 15 caregivers because of severe illness and/or death of the BMT

T1 recipient. Table 1 displays the demographic information of the sample of caregivers as well as the type of transplant for the recipient. All of the caregivers identified themselves as white. Most of the caregivers were female, employed full time, and had a college degree. The age of the caregivers ranged from 24 to 66 years at both time points, with a mean age of 47 years (Table 1). Approximately one-third of the committed partner/spouse caregivers
Table 1 Description of the Caregiver Sample

\begin{tabular}{|c|c|c|}
\hline & $\begin{array}{l}\text { During } \\
\text { Hospitalization } \\
\text { T1 (n= } 15)\end{array}$ & $\begin{array}{l}\text { Posthospitalization } \\
\text { T2 }(\mathrm{n}=9)\end{array}$ \\
\hline & Mean (SD) & Mean (SD) \\
\hline \multirow[t]{2}{*}{ Age, y } & $47.7,12.3$ & $47.5,13.6$ \\
\hline & n (\%) & n (\%) \\
\hline \multicolumn{3}{|l|}{ Gender } \\
\hline Female & $9(60)$ & $6(67)$ \\
\hline Male & $6(40)$ & $3(33)$ \\
\hline \multicolumn{3}{|l|}{ Type of relationship } \\
\hline Partner/spouse & $14(93)$ & $8(89)$ \\
\hline Significant other & $1(7)$ & $1(11)$ \\
\hline \multicolumn{3}{|l|}{ Children in the home } \\
\hline Yes & $5(33)$ & $2(22)$ \\
\hline No & $10(67)$ & $7(78)$ \\
\hline \multicolumn{3}{|l|}{ Education } \\
\hline $\begin{array}{l}\text { High school } \\
\text { graduate or less }\end{array}$ & $3(20)$ & $3(33)$ \\
\hline $\begin{array}{l}\text { Vocational/technical } \\
\text { or some college }\end{array}$ & $5(33)$ & $2(22)$ \\
\hline $\begin{array}{l}\text { Four-year college } \\
\text { graduate }\end{array}$ & $2(13)$ & $1(11)$ \\
\hline Graduate & $5(33)$ & $3(33)$ \\
\hline \multicolumn{3}{|l|}{ Employment } \\
\hline Full time & $9(60)$ & $5(56)$ \\
\hline Part time & $1(7)$ & $1(11)$ \\
\hline Retired & $3(20)$ & $2(22)$ \\
\hline Homemaker & $2(13)$ & $1(11)$ \\
\hline \multicolumn{3}{|l|}{$\begin{array}{l}\text { Type of bone marrow } \\
\text { transplant (recipient) }\end{array}$} \\
\hline Autologous & $12(80)$ & $7(78)$ \\
\hline Allogeneic & $3(20)$ & $2(22)$ \\
\hline
\end{tabular}

interviewed at T1 had 1 to 3 children younger than 18 years living in the home.

\section{- Pretransplant Phase}

In an effort to understand their "transplant story" we began each interview by asking the committed partner/spouse caregiver how they came to the decision to proceed with a BMT. In doing so, it was our goal to learn more about the pretransplant experience and decision making that went into proceeding with the potentially life-altering transplant experience. From these interviews, it became very clear that there was an overwhelming sense of uncertainty related to the decision to proceed with a BMT. Two overriding themes emerged as most salient in deciding to proceed with transplant: "conclusion that there was no other option" and "hope for a future."

\section{Conclusion That There Was No Other Option}

Many caregivers said that they did not really have any other option but to proceed with having the transplant. This sentiment was 
mostly expressed by caregivers who believed that all other treatment options had been exhausted. As one succinctly stated, "They told us, he had a $40 \%$ chance that it might work, but we didn't care because otherwise he had none." These caregivers expressed confidence and trust in their physicians and believed that the BMT was the next step in the treatment process. One reflected that "they more or less told us that this is what we really ought to do." Caregivers stated that information about their loved ones' disease, the recipient's current health status, and limited treatment options were all factors that led them to the conclusion that there was no other option but to proceed with the BMT.

\section{Hope for a Future}

For some of the families, the BMT was also viewed as an important source of hope for a future. One caregiver explained that the BMT was the best option because it was "the closest thing to a cure that you can do." Interestingly, regardless of prior treatment history, current health status of their partner/spouse, and the knowledge that the treatment used in BMT was quite arduous, most of the caregivers interviewed acknowledged that this treatment represented the best hope for a future together.

\section{Underlying Themes Across the BMT Trajectory: Uncertainty and Need for Information}

Our interviews identified uncertainty and the need for more information as 2 major and underlying themes across the BMT

T2 trajectory. Table 2 provides interview excerpts that elucidate these themes.

\section{Uncertainty}

During the prehospitalization phase, caregivers said that the "waiting and not knowing" had really taken a toll on them. One explained, "We dreaded it, but we were ready to get it done; done and over with because we knew we had to do it." Another caregiver described the time during the transplant as "It has really been scary. You don't know if he's going to get worse or if you're going to lose him." Many caregivers described the BMT hospitalization as "being on a roller coaster." One-minute things would seem fine, and then the next, they could change drastically. This uncertainty during transplant was identified by a number of caregivers as "the worst part." One stated, "It's really unpredictable. You just don't know what's going on from one moment to the next." Another expressed apprehension posttransplant when his spouse was finally released to home: "You just kind of wait to see what if any bad stuff will happen next." Uncertainty about the outcome of the BMT was evident at each phase in the BMT trajectory, even after returning home. Table 2 provides additional interview excerpts regarding the types of uncertainties experienced by caregivers prior to, during, and post-BMT.

\section{- Need for Information}

Although most of the caregivers thought the healthcare team had explained the BMT process and what to expect; few felt fully prepared for the experience. One reported, "It was harder than I thought it would be." Many caregivers identified accurate and timely information as essential to reducing their fears and uncertainties. In fact, many praised the medical and nursing staff for keeping them informed of changes during their loved ones

\section{Table 2 - Excerpts from Caregiver Interviews Regarding Specific Areas of Uncertainty Prior to, During,}

and Posthospitalization

\begin{tabular}{|c|c|c|c|}
\hline & Prior to Hospitalization $(\mathrm{n}=15)$ & Hospitalization ( $\mathrm{n}=15$ ) & Posthospitalization T2 ( $\mathrm{n}=9$ ) \\
\hline \multirow[t]{3}{*}{ Uncertainty } & $\begin{array}{l}\text { "Just the unknown and the anxiety } \\
\text { of not knowing what's going } \\
\text { to happen and not really } \\
\text { understanding everything..." }\end{array}$ & $\begin{array}{l}\text { "This is just driving us insane because } \\
\text { there's no way to plan. You can't } \\
\text { plan for tomorrow, let alone next } \\
\text { week or next month. That has } \\
\text { driven me absolutely crazy." }\end{array}$ & $\begin{array}{l}\text { "The waiting... trying to see if she's in } \\
\text { remission... so the waiting, just } \\
\text { waiting and waiting and waiting and } \\
\text { waiting..." }\end{array}$ \\
\hline & $\begin{array}{l}\text { "'Is he going to survive?"” and } \\
\text { I was thinking you know, 'am I } \\
\text { going to have a husband? Are we } \\
\text { going to be able to have kids?"” }\end{array}$ & $\begin{array}{l}\text { "The big picture, it's just overwhelming } \\
\text { and staggering, imagining him not } \\
\text { being here. So I choose not to ever go } \\
\text { there. You know I just, basically I } \\
\text { don't have the emotional wherewithal } \\
\text { right now to go there. So I don't." }\end{array}$ & $\begin{array}{l}\text { "All of these bills keep on coming, } \\
\text { and I'm like 'Oh my God, how am } \\
\text { I going to pay them?"” }\end{array}$ \\
\hline & & $\begin{array}{l}\text { "We've never been through this before so } \\
\text { we need to be told that this is normal } \\
\text { (medical symptoms/complications), } \\
\text { and this is, this is expected." }\end{array}$ & $\begin{array}{l}\text { "I kept having nightmares that I'd get } \\
\text { up, and she would be like, maybe not } \\
\text { there, or maybe she wouldn't be } \\
\text { sleeping... I just kept freaking out } \\
\text { that she would die while she was } \\
\text { sleeping, so I kept going in there } \\
\text { every night and like listening to her } \\
\text { breathe for a little while." }\end{array}$ \\
\hline
\end{tabular}


hospitalization. "It really helps that they keep you informed on what's going on. That makes a big difference. They don't leave you in the dark... you are not just another number. They treat you like you're somebody, like they really care," stated a male caregiver. Another expressed the same sentiment, stating "I mean every time I needed help, you know, with anything I would call there, and my questions were answered." Although most of the caregivers expressed satisfaction with the quality of information during BMT hospitalization, some expressed the need to have more information before and after hospitalization to improve continuity of care. Table 3 shows some of the information needs identified by caregivers based on their multiple roles prior to, during, and after hospitalization.

\section{- Caregiver Roles}

Caregivers reported feeling overwhelmed with juggling multiple roles and responsibilities. Based on the interviews, we classified these roles into 3 major categories: (a) "interpreter," which included obtaining and translating medical information to the patient, family, and social network; (b) "organizer," which included arranging and coordinating medical appointments (before and after BMT) for the patient and also managing the needs of immediate (especially children) and extended family members and friends; and (c) "clinician," which included assessing and identifying changes in their partner, with many reporting that they had to be "vigilant" about or "on top of" any changes in addition to providing care.

\section{Interpreter}

One key role that the caregiver performed was that of an "interpreter," which included obtaining, interpreting, and disseminating medical information to their partner, family, and social network. Often caregivers were enlisted to keep track of the medical care and advocate for the patient. For example, a caregiver explained that her husband wanted her to be there to help him understand his medical care: "He wants some answers... he wants me to get the answers because sometimes he couldn't really remember or sometimes he couldn't understand. So anytime they told him something he wanted me to come up there and listen to it and write it down so that I could then tell him." Caregivers also stated that they were responsible for relaying information to other family members and friends. The need to keep everyone informed was often identified as "difficult" and a source of significant "distress" for the caregiver.

\section{Organizer}

Caregivers reported that they felt primarily responsible for being the "organizer," which included arranging and coordinating medical appointments (before and after BMT) for the patient as well as meeting the needs of immediate family members (especially

Table 3 - Educational Needs Prior to, During, and Posthospitalization

\begin{tabular}{|c|c|c|c|}
\hline & Prior to hospitalization $(n=15)$ & Hospitalization $(n=15)$ & Posthospitalization T2 $(n=9)$ \\
\hline \multirow[t]{3}{*}{$\begin{array}{l}\text { Interpreter-medical } \\
\text { information }\end{array}$} & Type of transplant & $\begin{array}{l}\text { Implications of laboratory } \\
\text { values }\end{array}$ & Implications of laboratory values \\
\hline & Treatment plan & $\begin{array}{l}\text { Managing symptoms and } \\
\text { adverse effects }\end{array}$ & $\begin{array}{l}\text { Managing symptoms and adverse } \\
\text { effects }\end{array}$ \\
\hline & $\begin{array}{l}\text { Expected symptoms and } \\
\text { adverse effects }\end{array}$ & & $\begin{array}{l}\text { Information regarding seeking } \\
\text { medical treatment }\end{array}$ \\
\hline \multirow[t]{4}{*}{$\begin{array}{l}\text { Organizer-providing } \\
\text { support to patient } \\
\text { and others }\end{array}$} & $\begin{array}{l}\text { Information regarding setting } \\
\text { up online care pages }\end{array}$ & $\begin{array}{l}\text { Information regarding key time } \\
\text { points during treatment }\end{array}$ & $\begin{array}{l}\text { Need for follow-up } \\
\text { appointments-addressing } \\
\text { scheduling and transportation }\end{array}$ \\
\hline & $\begin{array}{l}\text { Hospital orientation-support } \\
\text { and rules of the bone marrow } \\
\text { transplant unit }\end{array}$ & $\begin{array}{l}\text { Psychosocial support for } \\
\text { caregiver; available } \\
\text { resources in communicating } \\
\text { with family members } \\
\text { about patient condition }\end{array}$ & $\begin{array}{l}\text { Support and education in } \\
\text { managing patient/family duties, } \\
\text { routines, and responsibilities } \\
\text { when patient returns home }\end{array}$ \\
\hline & $\begin{array}{l}\text { Information regarding financial } \\
\text { considerations }\end{array}$ & $\begin{array}{l}\text { Further information regarding } \\
\text { preparation for patient } \\
\text { return "home" }\end{array}$ & \\
\hline & $\begin{array}{l}\text { Psychosocial guidance regarding } \\
\text { communication with patient } \\
\text { and family about upcoming } \\
\text { bone marrow transplant } \\
\text { and preparations }\end{array}$ & & \\
\hline \multirow[t]{3}{*}{ Clinician-providing care } & Effective hand washing & Isolation procedures & $\begin{array}{l}\text { Medication administration - oral } \\
\text { and sometimes intravenous solutions }\end{array}$ \\
\hline & Central-line dressing change & Oral hygiene practices & $\begin{array}{l}\text { Information about assisting patient } \\
\text { with activities of daily living }\end{array}$ \\
\hline & Central-line maintenance & & \\
\hline
\end{tabular}


children) and also extended family members and friends. As might be expected, male caregivers expressed more concerns regarding maintaining the household. As one explained, "It's like another job now... I mean [she] absolutely ran the house... she runs a tight ship. The house was immaculate. She keeps everything cleaned up, all the time jockeying the kids around, so that is the hardest thing without her there.” Another male caregiver explained that it was a significant realization for him how much he had counted on his wife. He stated, "You don't realize how much somebody was doing until they aren't there, and you have to do it all."

\section{Clinician}

The caregivers discussed at length that they felt responsible for assessing and identifying changes in the patient, with many reporting that they had to be "vigilant" regarding or "on top of" changes in their partner's status. Interestingly, caregivers identified the need to be vigilant about changes in health status both during hospitalization and after returning home. One male caregiver adamantly recommended that "you really have to have someone watching out for you, and asking [questions]." He truly believed that he was partly responsible for "running her medical care." This caregiver was not alone in his interpretation. Many said that they seemed to have to take a leadership role in asking questions and advocating for their partner. One reported, "I absolutely feel like you have to be here [at the transplant center] ... I can't go home, I can't go home to get sleep... I haven't been to work for days." This strong sense of responsibility brought with it some guilt and anxiety when the caregiver could not be at the hospital all the time or as much as he/she had wanted.

All of the caregivers relayed their concerns regarding being responsible for providing "clinical care." Many reported worries about providing central line site care at home both before and after the BMT. For example, one stated, "every step of it seems so dire because mistakes could lead to an infection." Caregivers found that they were constantly questioning themselves. For example, one stated she repeatedly asked herself, "Are you doing it right? Are your hands clean?" Many also expressed fear about this new technical role, including statements such as "It scared me... how much that the responsibility was on me, and if I did something wrong would I hurt him?" Another female caregiver stated, "I had to be a nurse to him. I hated it because I was so afraid that I would screw something up." The weight of this responsibility was compounded when instructions were unclear or when procedures changed. Caregivers also expressed concern that providing clinical care was at times upsetting for their partner. For example, one said that giving shots to her husband was humiliating for him, which in turn was very distressful for her.

\section{Greatest Challenges}

In this study, we were also specifically interested in the caregivers' perceptions of the greatest challenges faced during BMT. Based on their reports, the most challenging aspects of their role across the BMT trajectory were categorized into 2 themes that we labeled: "being there and being strong for everyone" and "finding balance." Our goal was to understand the challenges of BMT caregivers so that we could use this information to develop evidence-based caregiver interventions.

\section{Being There and Being Strong for Everyone}

Caregivers reported that it was very important to them that they stay strong and not show their partner their concern and fears. As one said, "If something worries me I will not tell him because I don't want him to have that extra stress." The caregivers also discussed how hard it was for them to see their loved one go through the treatment. For example, one shared how difficult it was seeing her husband in pain, describing it as follows: "It was like somebody put a knife to you and just kept turning it. I knew how much he was hurting, and I couldn't cry in front of him, and I won't because I don't want him to feel how it affected me... but it shook me up." Many of the caregivers similarly reported that they had to hide their emotions from others, and they could not let their true feelings show through.

Caregivers with children additionally expressed significant concern regarding their adequacy as a parent, specifically their availability in meeting both the day-to-day demands and the emotional needs of their children without their spouse. For example, 1 male caregiver identified his biggest concern was parenting his children and the impact the BMT was having on them. He explained that they were used to their mother and that she could "deliver things to them that I can't ... or that I'm not used to." A female caregiver stated that the diagnosis of cancer had had a significant impact on her children. "It's been a really big change in their world... and very unsettling." The caregivers with children clearly expressed that the BMT had had an impact on the entire family, and they felt they needed more resources and guidance to help their children through this time.

\section{Finding Balance}

Many of the caregivers reported that with the absence of their significant other during transplant and with their increasing roles, it was harder to "have some balance" in their life. As one reported, "You're not really thinking about yourself anymore. It's just more; all of your attention is on the other person." Another caregiver became emotional, explaining "I have to go to the hospital all the time, and I still have to work, and then I feel guilty if I don't come, so that's been hard. I don't get to do the things that help me." Many of the caregivers were overwhelmed with the demands of not only caring for their partner but being the primary and often sole person coordinating other family responsibilities. For example, one reported, "You know, I have been living under a lot of stress. It seems like life is kind of evaporating into doctors and treatments."

\section{a Positive Findings}

\section{Social Support}

Caregivers identified social support as an invaluable resource for coping with the stressors across the BMT trajectory. Almost all of the caregivers identified family or very close friends as essential to 
meeting the demands of caregiving. Family members and/or friends played an important role as being persons they could confide in as well as sources of some respite. For example, 1 caregiver stated, "I'd say more than anything you need family there, even if it is to come in and out... at least give you a little break or somebody to talk to." Others identified the support of the nurses or other BMT transplant families as helping them deal with the stressors of BMT.

\section{Positive Growth}

Throughout this demanding experience, almost all of the caregivers said that the experience with a life-threatening illness had changed them. Many found that, although they would not wish the BMT experience on others, they had in fact found some benefits from having gone through it. For example, a caregiver explained, "The gift of crisis is that it forces you to sharply focus on what is important and what isn't, whether it's on relationships, values, what you want your life to be about. It forces you to do it because you don't know what the future will bring." In addition, many found that their relationships with their partner had gotten stronger: "I would say we talk more... we listen more." Another caregiver relayed, "I think going through this, it makes people kind of wake up and appreciate things a little better, appreciate a lot of things more. You don't take things for granted...." Others identified the need to reorder their lives. For example, 1 caregiver stated, "I think we're going to step back and kind of enjoy life. Don't keep being on the run. I mean, there's always another day, and you know we try to do too much in 1 day, and I think it's going to help us down the road a lot." Another explained that now that they were through the transplant they could "restart their lives" and plan for their future together, including starting a family. Still others found that the experience had improved their faith, with one stating, "I think that this has brought us closer to God." In fact, most expressed that their "trust in the Lord" had helped them cope with the stress of BMT.

\section{Discussion}

The purpose of this article is to present data from the perspective of the committed partner/spouse caregiver that will build the science and understanding of the BMT experience across the treatment trajectory from prehospitalization to up to 4 months after hospitalization. Caregivers agreed that the decision to proceed with BMT was based on their conclusion that there was no other option, and/or it provided the best hope for a future together. Because of the nature and complexity of BMT, caregivers' reports revealed 2 main underlying themes: uncertainty and need for information, which cut across all phases of the BMT trajectory. Caregivers identified living with the uncertainty as the hardest part of the BMT process. These findings build on a previous study by Wilson and colleagues, ${ }^{3(\mathrm{PE} 15)}$ who reported that spouses described the uncertainty during BMT hospitalization as "riding a rollercoaster in the dark." Our study adds to the literature in this area and documents that the feelings of uncertainty do not diminish after discharge and that the concerns regarding the partner's health remain after returning home. Caregivers emphasized that information was crucial to address uncertainty throughout the BMT trajectory. This suggests that it is imperative that nurses not only assess the patient's learning needs, but also explore the caregiver's needs at each phase of the treatment trajectory. Researchers have found that caregivers are instrumental in the outcomes of BMT recipients. ${ }^{7}$ In addition, studies have shown that providing adequate and timely information may enhance feelings of security ${ }^{15}$ and personal control, which in turn has been shown to reduce emotional distress in caregivers over the acute phase of BMT. ${ }^{2}$ These findings also support the need for developing a comprehensive cancer care plan that ensures smooth transitions and improves the quality of outcomes for cancer survivors and their families. ${ }^{19}$

\section{- Caregiver Roles}

Caregivers reported juggling multiple roles, which were categorized and labeled as "interpreter," "organizer," and "clinician." Similar results were found by Wilson and colleagues, ${ }^{3}$ who found that the caregiver role often evolved from simply being at the spouse's side to providing emotional support and physical care during the BMT hospitalization. We also noted that the demands of the caregiver role were complicated by the need to "be strong for everyone" and often resulted in the caregivers having difficulty in "finding balance" in their lives. The findings described here are similar to what Skaff and Pearlin ${ }^{20}$ refer to as "role engulfment," that is, when the roles one assumes and the demands of those roles profoundly alter the organization of daily life and may even reshape self-concept. The loss of self can have a significant impact on the caregiver's well-being. Researchers have found that caregivers report clinically significant levels of distress, anxiety, depression, and poor quality of life. ${ }^{2,8-11}$ On the other hand, Fife and colleagues ${ }^{2}$ reported that those caregivers of BMT recipients who had greater feelings of personal control, a greater sense of spiritual connectedness, less disruption in their lives, and less use of avoidance coping had significantly less distress than did their counterparts. Taken together, interventions to enhance coping strategies for caregivers focusing on increasing perceptions of personal control, enhancing spiritual connectedness, and efforts to maintain routine may be most advantageous.

\section{- Impact on the Family}

This research also clearly identified that the BMT had an impact on the entire family. Caregivers reported one of their greatest concerns to be the impact the BMT had on their children. Researchers have shown that children of cancer patients may experience both behavioral and emotional disturbances during the parent's illness. ${ }^{21}$ Specifically, a recent study of children of BMT recipients found that emotional distress remained above the norm throughout the BMT trajectory. Furthermore, emotional distress was significantly lower for children who experienced less disruption within the family structure such as changes in roles, routines, and patterns in family functioning. ${ }^{22}$ Therefore, while it is often difficult, efforts to maintain family routines can help provide a sense of normalcy for 
children of patients receiving a BMT. ${ }^{23}$ Future research needs to focus on interventions to support the entire family across the BMT trajectory.

Upon reflection and after the BMT, caregivers also acknowledged that the experience had had some positive aspects. Caregivers were quick to identify the important role that family and friends played in providing both emotional and instrumental support. In fact, they stressed that this was an essential coping resource. In addition, some caregivers believed that this experience had enhanced their spirituality and believed their faith was stronger for having come through this life-changing event. Similar findings were noted by Fife and colleagues, ${ }^{2}$ who reported that those caregivers who had a greater sense of spiritual connectedness also had lower levels of emotional distress. And finally, caregivers reported that they were more appreciative of life and/or had reordered their life to focus more on things that really mattered, such as family. This type of growth after a life-threatening experience such as cancer has been noted by survivors. ${ }^{25}$ This finding of benefits or the ability to draw on the positive aspects of a traumatic experience has been linked to overall improvement in quality of life of cancer survivors and their families. ${ }^{25}$

Although these data offer many insights into understanding the BMT experience across the early trajectory from the perspective of the committed partner/spouse caregiver, the study was limited by its sample characteristics. Most of the caregivers were women. Recent research suggests that children in families where the BMT recipient was female (mother) resulted in greater levels of emotional distress. ${ }^{22}$ Further research with larger samples that have equal numbers of male and female caregivers is needed to explore the impact of this on coping in BMT families. In addition, future longitudinal, prospective, mixed-methods studies should be conducted to explore coping and adaptation of BMT families longterm. Quantitative studies have demonstrated significant levels of distress even 1 year after transplant ${ }^{2}$; however, this work often failed to identify the cause of the distress. Future studies that explore these causes will improve our understanding and lead to interventions to improve outcomes and quality of life of BMT patients, caregivers, and families.

\section{a Conclusion}

Overall, these data provide further evidence of the significant and broad impact of BMT across the treatment trajectory as perceived by the caregiver. Findings indicate that managing uncertainty through education and support is essential for coping in the early phases of the BMT trajectory. The caregivers are tasked with multiple roles and responsibilities and will need informational, emotional, and instrumental support to effectively cope with the complexity and demands of caring for their spouse or significant other. Further longitudinal research is needed to clearly identify interventions that may be effective in supporting coping after BMT.

\section{References}

1. Pasquini M, Wang Z. Current use and outcome of hematopoietic stem cell transplantation: CIBMTR Summary Slides, 2013 Web site. http://www.cibmtr .org. Accessed September 12, 2014.
2. Fife BL, Monahan PO, Abonour R, Wood LL, Stump TE. Adaptation of family caregivers during the acute phase of adult BMT. Bone Marrow Transpl. 2009;43:959-966.

3. Wilson ME, Eilers J, Heermann JA, Million R. The experience of spouses as informal caregivers for recipients of hematopoietic stem cell transplants. Cancer Nurs. 2009;32(3):E15-E23.

4. Williams LA. Whatever it takes: informal caregiving dynamics in blood and marrow transplantation. Oncol Nurs Forum. 2007;34(2):379-387.

5. Frey P, Stinson T, Siston A, et al. Lack of caregivers limits use of outpatient hematopoietic stem cell transplant program. Bone Marrow Transpl. 2002; 30(11):741-748.

6. Foster LW, McLellan LJ, Rybicki LA, Dabney J, Copelan E, Bolwell BJ. Validating the positive impact of the in-hospital lay care-partner support on patient survival in allogeneic BMT: a prospective study. Bone Marrow Transpl. 2013;48:671-677.

7. Foster LW, McLellan LJ, Rybicki LA, Sassano DA, Hsu A, Bolwell BJ. Survival of patients who have undergone allogenic bone marrow transplantation: the relative importance of in-hospital lay care-partner support. J Psychosoc Oncol. 2004;22:1-20.

8. Eldredge DH, Nail LM, Maziarz RT, Hansen LK, Ewing D, Archbold PG. Explaining family caregiver role strain following autologous blood and marrow transplantation. J Psychosoc Oncol. 2006;24(3):53-74.

9. Langer SL, Abrams JA, Syrjala KL. Caregiver and patient marital satisfaction and affect following hematopoietic stem cell transplantation: a prospective longitudinal investigation. Psychooncology. 2003;12:239-253.

10. Langer SL, Yi JC, Storer BE, Syrjala KL. Marital adjustment, satisfaction and dissolution among hematopoietic stem cell transplant patients and spouses: a prospective, five-year longitudinal investigation. Psychooncology. 2010;19: 190-200.

11. Wulff-Burchfield EM, Jagasia M, Savani BN. Long-term follow-up of informal caregivers after allo-SCT: a systematic review. Bone Marrow Transpl. 2013;48: 469-473.

12. Bishop M, Beaumont JL, Hahn EA, et al. Late effects of cancer and hematopoietic stem cell transplantation on spouses or partners compared with surviovrs and survivor matched controls. J Clin Oncol. 2007;20(11): 1403-1411.

13. Bishop M. Psychosocial sequelae of hematopoietic cell transplantation in survivors and caregivers. Biol Blood Marrow Transplant. 2009;15:29-32.

14. Meehan KR, Fitzmaurice T, Root L, Kimtis E, Patchett L, Hill J. The financial requirements and time commitments of caregivers for autologous stem cell transplant reipients. J Support Oncol. 2006;4:187-190.

15. Stetz KM, McDonald JC, Compton K. Needs and experiences of family caregivers during marrow transplantation. Oncol Nurs Forum. 1996;23(9): 1422-1427.

16. Kim Y, Given BA. Quality of life of family caregivers of cancer survivors. Cancer. 2008;112:2256-2568.

17. Sandelowski M. What happened to qualitative description? Res Nurs Health. 2000;23(3):334-340.

18. Hsieh H, Shannon S. Three approaches to qualitative content analysis. Qual Health Res. 2005;15(9):1277-1288.

19. McCabe M, Bhatia S, Oeffinger KC, et al. American Society of Clinical Oncology statement: achieving high quality survivorship cancer care. J Clin Oncol. 2013;31(5):631-640.

20. Skaff MM, Pearlin LI. Caregiving: role engulfment and the loss of self. Gerontologist. 1992;32(5):656-664.

21. Osborn T. The psychosocial impact of parental cancer on children and adolscents: a systematic review. Psychooncology. 2007;16:101-126.

22. Spath M, Fife BL, Monahan P, et al. Children's emotional adaptation to parental BMT. Bone Marrow Transpl. 2013;48:135-140.

23. Houldin A. A qualitative study of caregivers experiences with newly diagnosed advanced colorectal cancer. Oncol Nurs Forum. 2007;34(2):323-330.

24. Huizenga HM, van der Graaf WTA, Hoekstra HJ, Hoekstra-Weebers JE. Psychosocial consequences for children of a parent with cancer: a pilot study. Cancer Nurs. 2004;26:195-202.

25. Antoni MH, Lehman JM, Klibourn KM, et al. Cognitive-behavioral stress management intervention decreases the prevalence of depression and enhances benefit finding among women under treatment for early-stage breast cancer. Health Psychol. 2001;20(1):20-32. 


\section{AUTHOR QUERY}

No Query. 